\title{
Impaired megakaryopoiesis and behavioral defects in mafG -null mutant mice
}

\author{
Jordan A. Shavit, ${ }^{1,3}$ Hozumi Motohashi, ${ }^{2,3}$ Ko Onodera, ${ }^{1,3}$ J un-etsu Akasaka, ${ }^{2}$ \\ Masayuki Yamamoto, ${ }^{2}$ and James Douglas Enge ${ }^{1,4}$ \\ ${ }^{1}$ Department of Biochemistry, Molecular Biology, and Cell Biology, N orthwestern University, Evanston, Illinois 60208-3500 \\ USA; ${ }^{2}$ Institute of Basic Medical Sciences and Center for TARA, University of Tsukuba, Tsukuba 305, Japan
}

\begin{abstract}
The small Maf proteins (MafG, MafK, and MafF), which serve as heterodimeric partner molecules of CNC family proteins for binding in vitro to MARE sites, have been implicated in the regulation of both transcription and chromatin structure, but there is no current evidence that the proteins fulfill these functions in vivo. To elucidate possible contributions of the small Maf proteins to gene regulation, we have ablated the mafG and mafK genes in mice by replacing their entire coding sequences with the Escherichia coli lacZ gene. mafG homozygous mutant animals exhibit impaired platelet formation accompanied by megakaryocyte proliferation, as well as behavioral abnormalities, whereas mafK -null mutant mice are phenotypically normal. Characterization of the mafG and mafK embryonic expression pattems show that their developmental programs are distinct and intersecting, but not entirely overlapping. These results provide direct evidence that the small Maf transcription factors are vital participants in embryonic development and cellular differentiation.
\end{abstract}

[Key Words: Small Maf proteins; gene knockouts; thrombocytopenia; neuronal deficit]

Received April 20, 1998; revised version accepted May 21, 1998.

The product of the maf proto-oncogene and its related family members (the Maf family proteins) share well conserved basic and leucinezipper (bZip) motifs that mediate DNA binding and dimer formation. Members of the Maf family are divided into two subfamilies: the large $\mathrm{M}$ af proteins, C-M af ( $\mathrm{N}$ ishizawa et al. 1989), M afB (Kataoka et al. 1994a), and N RL (Swaroop et al. 1992), all of which contain a distinctive acidic domain that enables transcriptional activation, and the small $\mathrm{M}$ af proteins, MafK (Fuji wara et al. 1993), M aff (Fujiwara et al. 1993) and M afG (Kataoka et al. 1995), which appear to consist of little more than the essential regions required for DN A binding and heptad repeat interactions.

Transcription factor NF-E2 is composed of two subunits, p45 and p18 (Andrews et al. 1993a,b; Igarashi et al. 1994), where the p18 subunit was shown to be a small Maf protein (for reviews, see Blank and Andrews 1997; Motohashi et al. 1997). Heterodimers of p45 and small Mafs can activate transcription from MAREs [M af recognition el ements, TGCT GAC(T/GT)CAGCA ], wheréas small $M$ a af homodimers form active repressors acting on the same sites ( $N$ agai et al. 1998). Adding to

\footnotetext{
${ }^{3}$ These authors contributed equally to this work ${ }^{4}$ Corresponding author.
}

E-MAIL d-engel @nwu.edu; FAX (847) 467-2152. this regulatory complexity, p45 was subsequently identified as only one member of a larger group of proteins that now constitute the mammalian cap'n'collar (CNC; Mohler et al. 1991) protein family - these are called p45, N rf1 (/LCRF1/TCF11), N rf2 (/ECH), Bach1, and Bach2 (Chan et al. 1993; Caterina et al. 1994; Luna et al. 1994; M oi et al. 1994; Itoh et al. 1995; Oyake et al. 1996). These five CNC family members display si milar heterodimeric interactions, but also include unique differences in transactivation potential in association with the small M af proteins (Itoh et al. 1995; Johnsen et al. 1996; Oyake et al. 1996). As noted original ly, the MARE al so encompasses a consensus AP-1 binding site (Engel 1994). It has been shown that the small $M$ af proteins can interact with c-Fos, whereas the large M afs can heterodimerize with c-Fos and/or C-Jun (Kataoka et al. 1994b, 1995). Therefore, the intersection of the A P-1 family proteins with the even larger number of potential $\mathrm{CNC} / \mathrm{smal}$ $M$ af interactions places these heteromeric transcription factors at the crux of a complicated, yet potentially exquisitely sensitive, regulatory network. One can envision how each of these proteins might contribute to a very sensitive "on/off" transcriptional switch, which could be finely titrated based simply on their relative activities inside cells at specific times during development (Engel 1994; M otohashi et al. 1997). 
Gene targeting has revealed distinct roles for several CNC family members in mammalian gene regulation. nrf1-null mutants display a nonautonomous defect in mesoderm formation and fail to devel op beyond embryonic day (E) 7.5 (Farmer et al. 1997). nrf2-null mutants, on the other hand, are viable (Chan et al . 1996; Itoh et al. 1997) but impaired in the xenobiotic inductive response of phase II drug detoxifying enzyme genes (Itoh et al. 1997). M ost germane to the present study, p45 homozygous mutant mice display profound thrombocytopenia as a result of impaired megakaryocyte differentiation, leading to postnatal death (Shivdasani et al. 1995).

Recently, the mouse mafK gene was disrupted by gene targeting. In contrast to p45 and nrf1-null mutants, however, the mafk mutant mice were viable, fertile, and apparently normal and heal thy (Kotkow and Orkin 1996). Because the small $M$ af proteins can functionally substitute for one another in vitro in the NF-E2 DN A-binding complex (Igarashi et al. 1994), it was suggested that another small $\mathrm{M}$ af protein might provide a complementing activity that rescues mafK homozygous mutant animals. This result was somewhat disquieting, however, as $M$ afK is not ubiquitous, but is restricted within well defined cell lineages (M otohashi et al. 1996), as are the two other small Maf proteins (J. Akasaka, in prep.). Therefore, the observation that the mafK germ-line mutation led to no phenotype raised the spectre that the small $M$ af proteins might not be required for $\mathrm{CNC}$ family interactions in vivo, and that the genuine partner molecule(s) required for $\mathrm{CNC}$ activation was yet to be defined.

To address this question, we explored the functional roles of $M$ afG and $M$ afK in the mouse by replacing the entire coding regions of both the mafG and mafK genes with the lac $Z$ gene. N o defects were observed in mafK ${ }^{-1-}$ mice, in accord with a previous report (Kotkow and Orkin 1996). In contrast, although mafG $^{-1-}$ animals were also viable and fertile, they exhibited abnormal megakaryocyte proliferation with accompanying thrombocytopenia, as well as behavioral defects. Furthermore, the mafG and mafK genes display almost perfectly complementary expression patterns in early embryos, and the patterns of both genes become more complicated from E8.5 onward.

These results show that although the small $M$ af proteins can compensate for some embryonic functions when they are expressed in the same tissue, other roles of the small Maf factors are complementary and therefore cannot be fully compensated. This is most readily apparent during megakaryopoiesis and neurogenesis, where mafG $^{-1-}$ animals display physiological defects from the loss-of-function mutation, thereby demonstrating for the first time that the small Maf proteins are physiologically required in vivo.

\section{Results}

Targeting of the mafG and mafK genes

To elucidate possible roles for the small $M$ af proteins in murine devel opment, we generated loss-of-function mu- tations in the mafG and mafK genes by deleting their entire coding sequences (J. Akasaka, in prep.; M otohashi et al. 1996). Targeting vectors were designed to replace the coding exons with selectable markers; in the case of mafG, loxP sites surrounded the MClneo/MC1HSVtk cassette (Fig. 1a), whereas for mafK, IoxP sites were placed around a phosphoglycerate kinase (PGK)-neo cassette (Fig. 1e). Immediately $5^{\prime}$ to these markers, and replacing the endogenous translation initiation sites present in each of the mafG or mafK second exons, the lac $Z$ gene was inserted, thereby allowing the small maf genes to be individually monitored by $X$-gal staining. Diphtheria toxin and thymidine kinase were used as negative selection markers in the mafG and mafK targeting cassettes, respectively (Fig. 1a,e).

R1 embryonic stem (ES) cells ( $N$ agy et al. 1993) were electroporated with the linearized targeting constructs, and for mafG targeting 19 of 456 colonies were identified as homologous recombinants by PCR (Fig. 1b); eight of these positive clones were confirmed by Southern blotting (Fig. 1c). In the case of mafK, five of 68 colonies were shown to be properly integrated by Southern blotting (Fig. 1f). All of the ES clones were confirmed by additional restriction enzyme digests and Southern blotting (data not shown). The selected clones were then aggregated with eight-cell diploid embryos. Two mafG and three mafK clones produced chimeras that passed the mutant al leles to first generation offspring. The chimeras were bred to both CD1 and C57BL/6J mice for subsequent studies (Fig. 1d,g).

mafK and mafG homozygous null mutant animals are viable and fertile

Heterozygous $F_{1}$ offspring were intercrossed and the resulting pups were examined and genotyped between birth and 2 weeks of age. The results of breeding experiments from the three mafK lines in the CDI background showed that they displayed a normal Mendelian ratio of offspring (Table 1). mafG homozygous mutant mice were born at a lower than expected ratio. This result was not statistically significant $(P>0.1)$ in the $C 57 B L / 6]$ background, but was in the CD1 background $(P<0.01$; Table 1). RNase protection experiments on samples taken from multiple tissues showed that both targeting events resulted in null mutations in the respective genes (H. Motohashi, unpubl.).

\section{Impaired thrombopoiesis in mafG mutant mice}

Because N F-E2 has been demonstrated to be a key regulatory molecule in thrombopoiesis (Shivdasani et al. 1995), and all previous literature suggested that the re quired partner for $\mathrm{p} 45$ was a small $M$ af molecule, we first analyzed the peripheral blood of mafG and mafK homozygous mutant animals. The platel et count was dramatically diminished in mafG mutant mice, whereas all other blood cell lineages were unaffected by the mutation (Table 2; data not shown). Furthermore, histological analysis revealed a threefold increase in the number of 
Figure 1. Targeted disruption of the mafG and mafK genes. (a) Structure of the mafG genomic locus, targeting vector, and targeted locus. (b) PCR screening of R1 ES cell clones using the primers whose positions are indicated by singl e headed arrows in a. (c) Southern bl ot confirmation of PCR positive and negative clones, using probe $1 \mathrm{G}$, a 1.6-kb BamHI-Sacl fragment. Clone 3E8 shows an additional band that was not seen after further expansion. (d) Southern blot of tail DNAs from litters of mafG $^{+1-}$ intercrosses, using probe 1G. (e) Structure of the mafk genomic locus, targeting vector, and targeted locus. (f) Southern blot screening of R1 ES cell clones, using probe $1 \mathrm{~K}$, a 6.6-kb Xbal fragment. (g) Southern blot of tail DNAs from litters of mafK ${ }^{+1}$ backcrosses, using probe 2K, a 1.3-kb SaclXbal fragment. (M) Mutant allele; (WT) wild-type allele. a wild-type mafG locus:

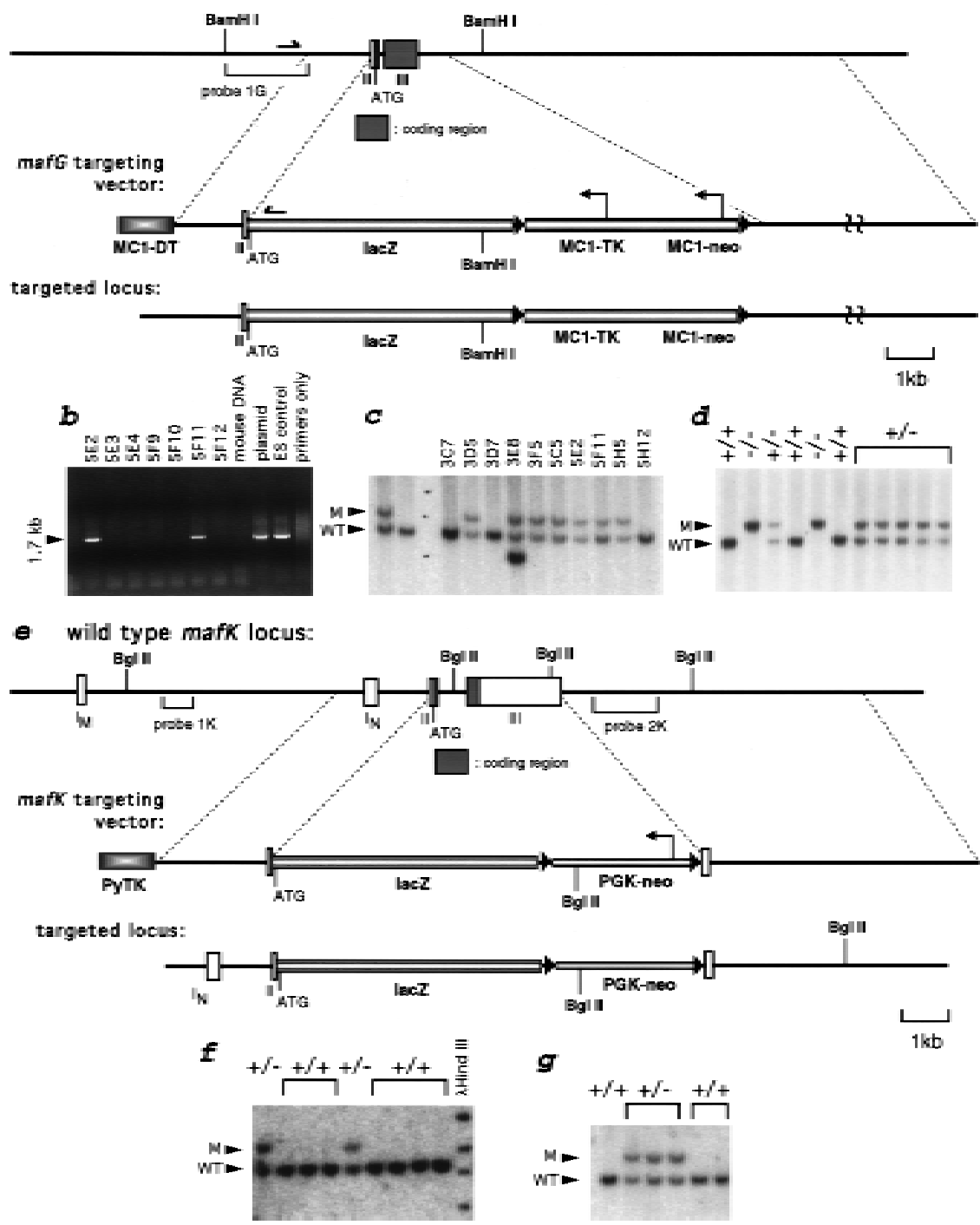

indicating a late differentiation block in megakaryocyte maturation, as is also the case for p45 mutant mice. In contrast, mafK ${ }^{+1-}$ and mafK ${ }^{-1-}$ mice exhibited normal hematopoietic parameters (Table 2; data not shown), consistent with earlier results (Kotkow and Orkin 1996). Therefore, $M$ afG is required for terminal differentiation

Table 1. Genotype ratios from heterozygous small maf mutant intercrosses

\begin{tabular}{|c|c|c|c|c|c|}
\hline Mutant & $H+$ & $H-$ & $-1-$ & Total & $\begin{array}{c}\chi^{2} \text { test } \\
(\mathrm{P})\end{array}$ \\
\hline \multicolumn{6}{|l|}{ mafG } \\
\hline C57BL/6J & 29 (29\%) & $53(52 \%)$ & 19 (19\%) & $101(100 \%)$ & $>0.1$ \\
\hline CD1 & 39 (36\%) & $53(49 \%)$ & $16(15 \%)$ & $108(100 \%)$ & $\varangle 0.01$ \\
\hline \multicolumn{6}{|l|}{ mafK } \\
\hline CD1(A3) & $12(15 \%)$ & $40(51 \%)$ & 27 (34\%) & 79 (100\%) & $>0.05$ \\
\hline CD1(B2) & $16(33 \%)$ & $24(50 \%)$ & 8 (17\%) & 48 (100\%) & $>0.1$ \\
\hline CD1(D1) & $30(26 \%)$ & $62(54 \%)$ & $23(20 \%)$ & 115 (100\%) & $>0.1$ \\
\hline
\end{tabular}

The mafG data are from one chimera crossed into either the C57BL/6 or CD1 genetic background. The mafK matings are for three different ES clones (in parentheses), all bred into the CDI background. 
Table 2. Hematopoietic analysis of the small maf mutants

\begin{tabular}{lcc}
\hline Genotype & $\begin{array}{c}\text { Platel et count } \\
\left(\times 10^{3} / \mu\right)\end{array}$ & $\begin{array}{c}\text { Megakaryocytes } \\
(\% \text { nucleated cells })^{a}\end{array}$ \\
\hline mafG $^{+-}$ & $1213.7 \pm 46.4$ & $0.050 \pm 0.017$ \\
mafG $^{-1-}$ & $541.7 \pm 48.4$ & $0.147 \pm 0.038$ \\
mafK $^{+-}$ & $1267.7 \pm 17.2$ & N.D. \\
mafK $^{-1-}$ & $1095.0 \pm 58.1$ & N.D. \\
\hline
\end{tabular}

Whole blood and bone marrow were harvested from mafG and mafK mutant littermates, and the platelet count and megakaryocyte percentage were determined on three different animals of each genotype (see $M$ aterials and $M$ ethods).

a(N .D.) N ot determined.

during thrombopoiesis, demonstrating for the first time a functional requirement for a small $M$ af protein.

Behavioral analysis reveals additional MafG functions in the nervous system

Further observations indicated that the mafG $^{-1-}$ pups might display deficits in addition to the one identified in hematopoiesis. These unexpected deficiencies appeared to be of neuronal origin, and were more obvious in the C57BL/6J than in the CD1 background, and therefore we report observations only in C57BL/6J mice.

The presumptive neurological defect was first noted when newly weaned mice were held inverted by the tail during cage changes, where homozygous mutant pups could be easily and uniformly identified by their response to handling. Instead of employing a typically smooth sideways motion to reach upward, as in their wild-type or heterozygous littermates, mafG $^{-1-}$ pups convulsively attempted to throw themsel ves into an upright position (data not shown). This behavior became less obvious as the mice aged (5- 6 months), but was replaced by a new behavior, clasping their hindlegs to- gether when inverted, another uncharacteristic response which is not observed in heterozygous littermates or wild type animals (Fig. 3a).

To quantify these behavioral abnormalities, we initially tested the animals in some simple behavioral tasks. mafG ${ }^{-1-}$ adults were permitted to grab a thin wire with their forepaws, and were then left to hang, and their responses examined. Wild-type or heterozygous mutant animals immediately grabbed the wire with their hindpaws and were able to hold themselves or balance on top of the wire for an average of $51 \mathrm{sec}$. The majority of homozygous mafG mutants, on the other hand, were unable to grasp the wire with their hindlimbs-they hung briefly before dropping to the surface below ( $T$ able 3). A second test, that would not so obviously require well developed musculature, was performed by placing the mice on a 10-ml glass pipette. The results were the same as for the wire hang task-nearly all mafG $^{-1-}$ animals were unable to support themselves for Ionger than $15 \mathrm{sec}$, whereas littermates could maintain this bal anced position for $1 \mathrm{~min}$ (the test time limit; Table 3).

To characterize the mafG mutant animals more extensively, we subjected them to a battery of additional neurol ogical tests (C rawley and Paylor 1997) and to open field testing. Heterozygous and homozygous mutants were indistinguishable in appearance (except in size, below) or gross neurological behavior in an empty cage; furthermore, in several additional tests (swimming, rearing, rolling, righting), mafG $^{+1-}$ and mafG $^{-1-}$ animals responded similarly. In the open field test, we found no statistically significant differences in time spent in the center or periphery of the field, number of squares traversed, number of rearings, freezing time, or number of fecal boli $\left(n=4\right.$ mafG $^{+1}-, n=8$ mafG $^{-1}$; data not shown). Therefore, the effect(s) of the mafG mutation on the nervous system, although very restricted, appears to be fully penetrant.

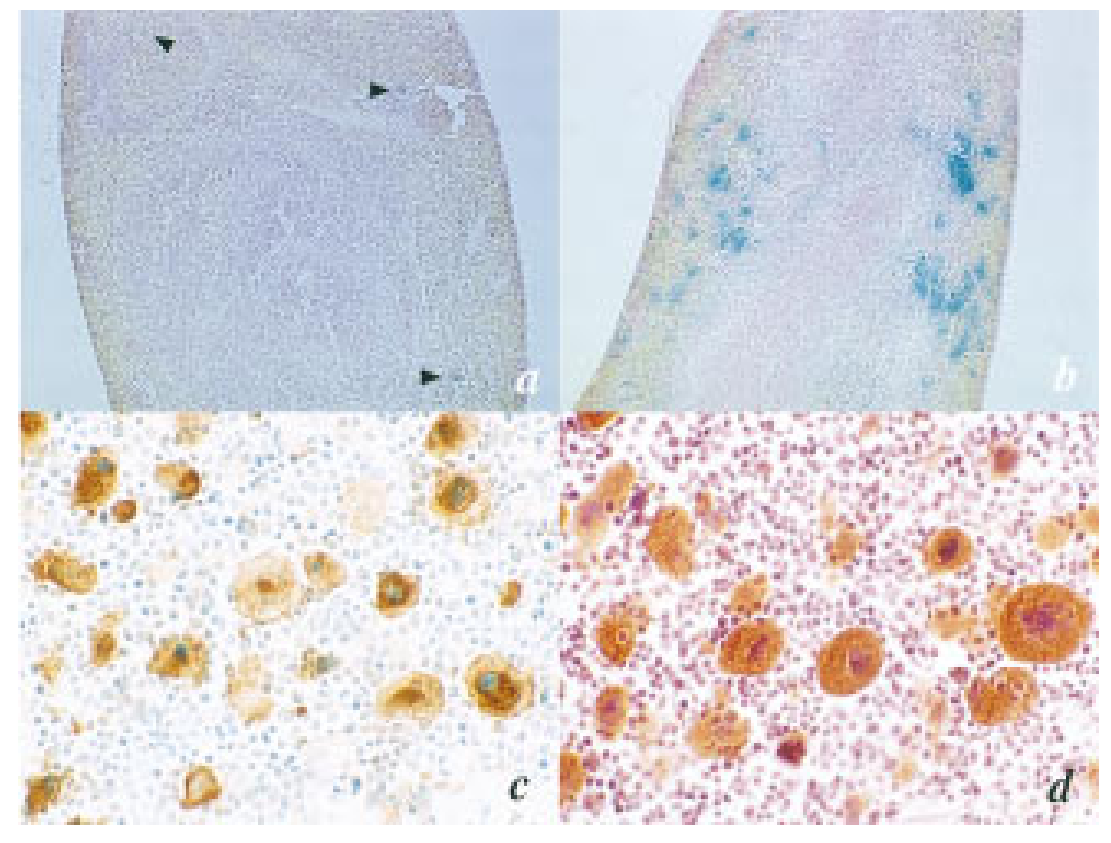

Figure 2. Stimulation of megakaryopoiesis in mafG mutant mice. (a) A transverse section through a mafG ${ }^{+-}$adult spleen shows few $\beta$-gal staining megakaryocytes (indicated by arrowheads). (b) A similar section through the spleen of a mafG ${ }^{-1-}$ littermate shows expansion of the megakaryocyte population. In addition, these show a dosage dependent increase in staining, attributable to the presence of one additional expressed copy of lacZ. mafG ${ }^{-1-}$ megakaryocytes from adult bone marrow are positive for anti-glycoprotein IIb antibody reactivity (c) and for acetylcholinesterase activity (d) Jackson 1973; Beckstead et al. 1986). 
Figure 3. Behavioral and weight deficits in mafG mutant animals. (a) Six-month-old mafG $^{+1-}$ (left) and mafG ${ }^{-1}$ (right) male littermates display wild-type and abnormal behaviors, respectively. Homozygous mutant animals spontaneously clench their hindl egs together when suspended in an inverted position. (b) A photograph of the mice in a shows that the mafG $^{-1-}$ mutant (right) is smaller than its heterozygous littermate (left). (c,d) Developmental profile of mafG postnatal weights in B6/129 background animals. Heterozygous ( $\square$ ) and homozygous $(\diamond)$ mutant littermates were weighed and averaged from the first week after birth up to 11 weeks of age.

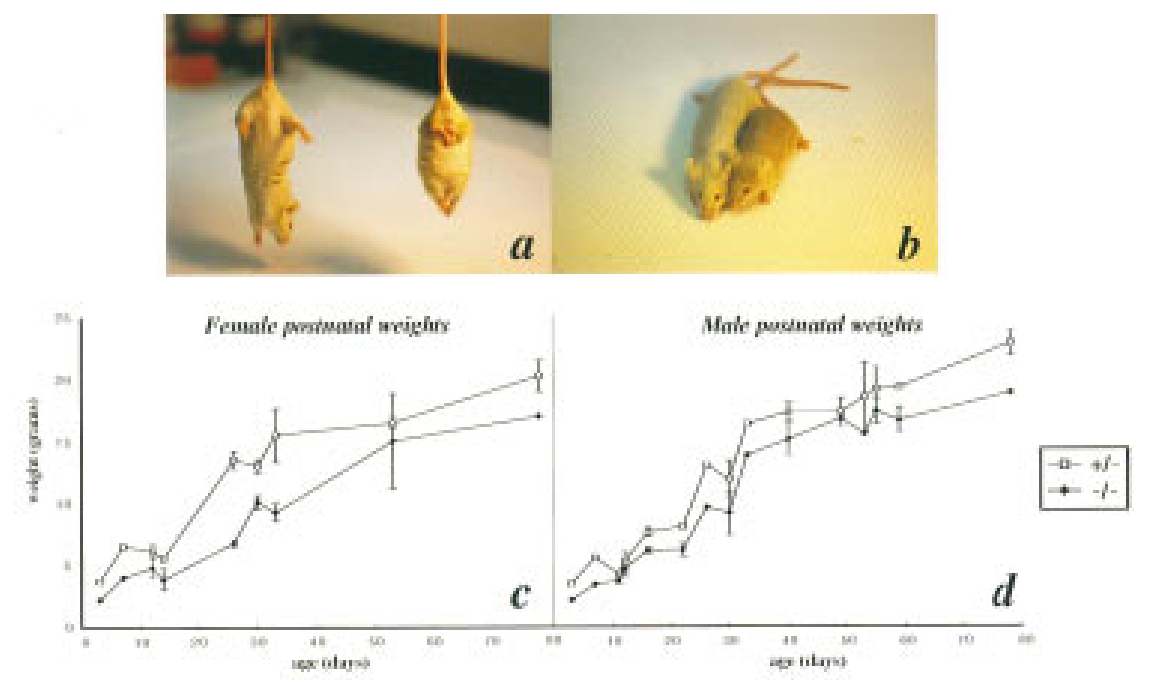

mafG homozygous mutants are subject to postnatal wasting

The small maf homozygous mutant animals survived beyond weaning with no apparent difficulty. Some mafG $^{-1-}$ animals, however, were obviously smaller than their littermates (Fig. 3b). This was quantified by weighing pups at different ages; mafG mutant pups showed a significant disparity from their littermates postnatally through adul thood. This was found in both the C57BL/6] (Fig. 3c,d) and CD1 (not shown) backgrounds. In almost all litters examined, homozygous mutant females weighed less than their littermates (Fig. 3c), but this phenotype was less penetrant for males (Fig. 3d). We averaged the weights of the wild-type and heterozygous animals (these two classes did not show any significant disparities) from individual litters, and then calculated the normalized percentage of each individual relative to its litter average for all time points examined. These values showed that mafG $^{-1-}$ females and males had respective mean weights of $71.2 \%$ and $82.3 \%$ of the mafG $^{+1+}$ and mafG $^{+1-}$ animals. Once again, mafK homozygous mutants exhibited no similar discrepancy (data not shown).

Complementary expression of the mafK and mafG genes during murine embryogenesis

To elucidate further the molecular mechanisms that might underlie the mafG gene null mutant-specific phenotypes, we characterized the mafG and mafK expression patterns using the inserted lac $Z$ genes as reporters to detect $\beta$-galactosidase ( $\beta$-gal) activity. The rationale for this analysis was that if the mafG-specific phenotypes were attributable to a lack of compensation by other small Maf proteins, we might be able to identify nonoverlapping sites of expression of both the mafG and mafK genes through such an analysis. Matings were therefore conducted between heterozygous animals of a mixed 129/CD1 background, and the litters were exam- ined at E6.5, E7.5, E8.5, E9.5, E10.5, E12.5, and E14.5. At stages after E9.5, embryos were genotyped by PCR.

Although differences were not observed either in embryonic development or in staining patterns between heterozygous versus homozygous mutant embryos, the homozygous mutants showed uniformly more intense staining (data not shown). In embryos that were not genotyped (before E9.5), three staining classes were observed-lesser staining (presumed to be heterozygous), more intensely staining (presumptive homozygous mutant), and no visible staining (classified as wild type).

At E6.5, to our surprise, mafG and mafk exhibited al most perfect mutually exclusive staining patterns (Fig. $4 a, b)$. A comparison of the mafG ${ }^{-1-}$ and mafK $^{-1-}$ wholemount stained embryos displayed an obvious and striking contrast-mafG and mafk expression clearly demarcated the epiblast/extraembryonic boundary. mafG was clearly expressed in the embryonic ectoderm and mesoderm, with very weak staining in extraembryonic tissues. In contrast, mafK mutant embryos intensely stained the ectoplacental cone and extraembryonic endoderm. Although the two genes shared a spotted staining pattern across the entire embryo, which was not observed in wild-type embryos (data not shown), it was unclear from this analysis al one whether or not the two spotted patterns overlapped. At E7.5, the expression pat-

Table 3. mafG mutant behavioral phenotypes

\begin{tabular}{lcc}
\hline Genotype & $\begin{array}{c}\text { Wire hang } \\
\text { time }(\mathrm{sec})\end{array}$ & $\begin{array}{c}\text { Balancing } \\
\text { time }(\mathrm{sec})\end{array}$ \\
\hline+- & $51 \pm 15$ & $47 \pm 21$ \\
$-1-$ & $17 \pm 21$ & $15 \pm 21$ \\
t-test & $\mathrm{P}=4.4 \times 10^{-7}$ & $\mathrm{P}=1.6 \times 10^{-4}$
\end{tabular}

mafG homozygous mutants and heterozygous littermates were subjected to the wire hang and balancing tasks, as described (M aterials and M ethods). 

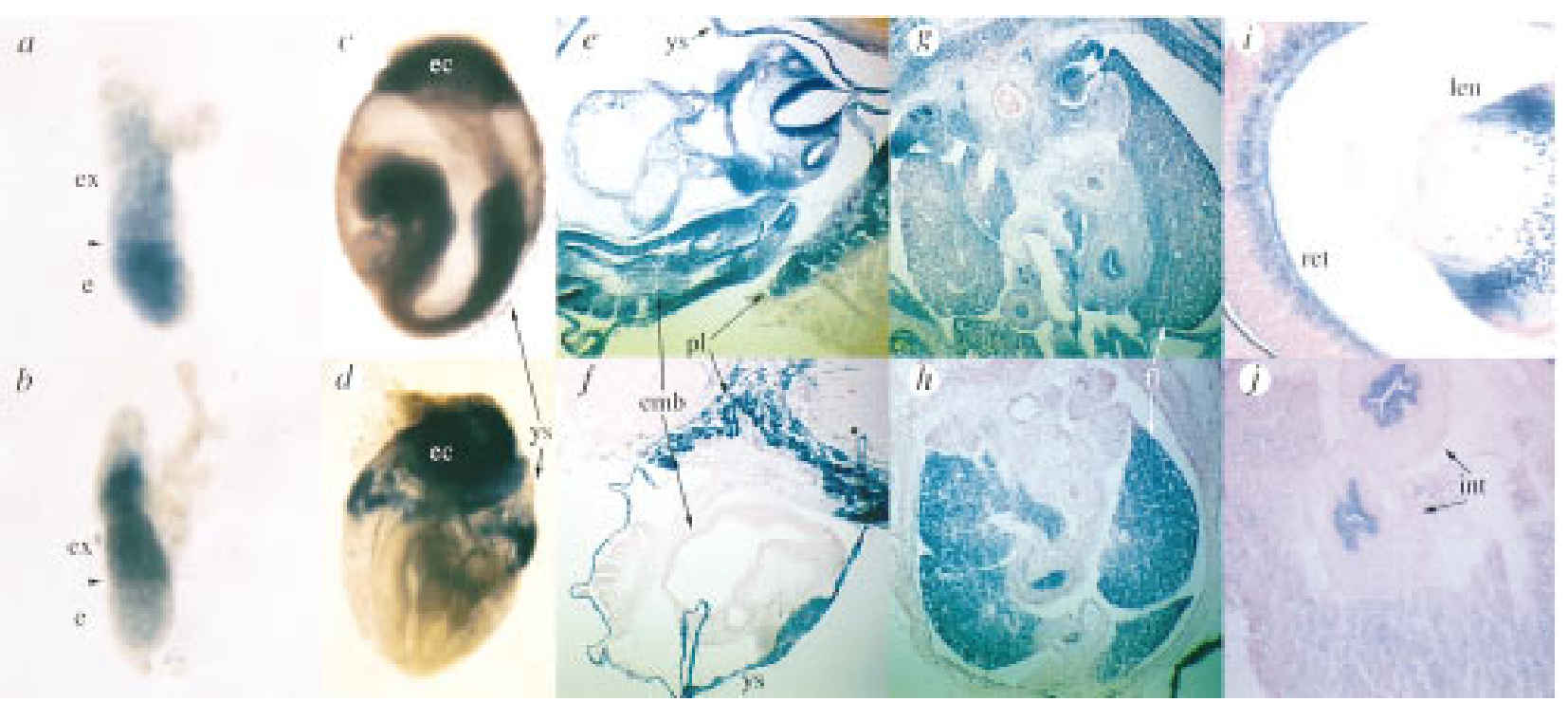

Figure 4. Embryonic expression patterns of mafG and mafK. mafG ${ }^{-1-}(a, c, e, g, i)$ and mafK ${ }^{-1-}(b, d, f, h, j)$ embryos were dissected, fixed, and stained for $\beta$-gal activity as described in Materials and methods. $(a, b)$ Whole-mounts of E6.5 embryos show that mafG expression is detected strongly in embryonic tissues, whereas mafK is predominantly extraembryonic. Both genes are expressed in a diffuse pattern in the complementary region of the embryos. (c,d) E8.5 embryos show that mafG and mafK continue to be embryonic and extraembryonic, respectively, with expansion of both into the ectoplacental cone, and mafK initiating expression in the yolk sac endoderm. (e,f) Transverse sections through E9.5 embryos indicate expression of mafG in the embryo, placenta, and yolk sac, with mafK limited to the placenta and yolk sac endoderm. (g,h) At E12.5, transverse sections of mafG and mafK stained embryos exhibit strong expression in the hematopoi etic compartment of the fetal liver. (i) A transverse section of an E14.5 embryo shows strong mafG staining in the developing lens and retina. (j) At E14.5, the strongest site of mafK expression is seen specifically in the intestinal epithelium. (A rrowheads in a and b) Embryonic/ extraembryonic boundary; (e) embryonic pole of the egg cylinder; (ex) extraembryonic pole of the egg cylinder; (ec) ectoplacental cone; (ys) yolk sac; (emb) embryo; (pl) placenta; (fl) fetal liver; (ret) retina; (len) lens epithelium; (int) intestine.

terns for both genes were essentially unchanged, with mafG expressed throughout most of the embryo and mafK expressed primarily in developing extraembryonic endoderm (data not shown).

At E8.5, mafG expression was still strong throughout the entire embryo, with especially intense staining in the neural tube. At this stage, the mafG pattern began to intensify in the ectoplacental cone but only weakly stained the extraembryonic tissues (Fig. 4c). This same pattern persisted into E9.5 (Fig. 4e), when weak staining in the yolk sac blood islands first became detectable. At E8.5, mafK staining was al so intense in the ectoplacental cone and in the yolk sac visceral endoderm (Fig. 4d). By E9.0 the entire yolk sac endoderm displ ayed very intense mafk staining. Weak neural tube expression of mafK became apparent, and this continued into E9.5 along with the yolk sac and ectoplacental cone staining (Fig. 4f). mafG continued to be expressed throughout almost the entire embryo at E9.5, E12.5, and E14.5 (Fig. 4g; data not shown). Some additional sites of particularly intense mafG expression were in the epithelium of the intestine, skeletal muscle, lens and retina, brain, and both cranial nerve and dorsal root ganglion cells (Fig. 4i; data not shown). In contrast to the quite broad embryonic expression of mafG, during this same period mafk was restricted to intense staining in the placenta, hematopoietic cells of the fetal liver (Fig. 4h), yolk sac endoderm, epithelium of the intestine (Fig. 4j), and the heart (data not shown).

After birth, both mafG and mafk were strongly expressed in the epidermis, hair follicles, epithelium of the digestive and respi ratory tracts, and kidney tubules (data not shown). Many of these are proliferating tissues, implying that the small $M$ af proteins may have particularly important roles in cell growth or division. In adult mice, mafG and mafK displayed expression in both overlapping as well as individually distinct tissues. In some, such as tubules of the kidney, both mafG and mafk were strongly expressed, but in other tissues, one was far more predominant (see below).

Differential expression of mafG and mafK suggests mechanisms for mafG ${ }^{-1-}$-specific phenotypes

As mafG mutant mice showed a specific thrombopoietic phenotype, we sought to investigate this defect further by analyzing $\beta$-gal activity in megakaryocytes synthesized in either mafG or mafK mutant animals. During embryonic development, at E12.5, we found that mafG (Fig. 5a) and mafK (Fig 5b) were both expressed strongly in differentiating megakaryocytes of the fetal liver, as well as in newborn pups (data not shown). Adult mice ( $>2$ months), however, showed differential expression. Whereas mafG was strongly expressed in adult mega- 


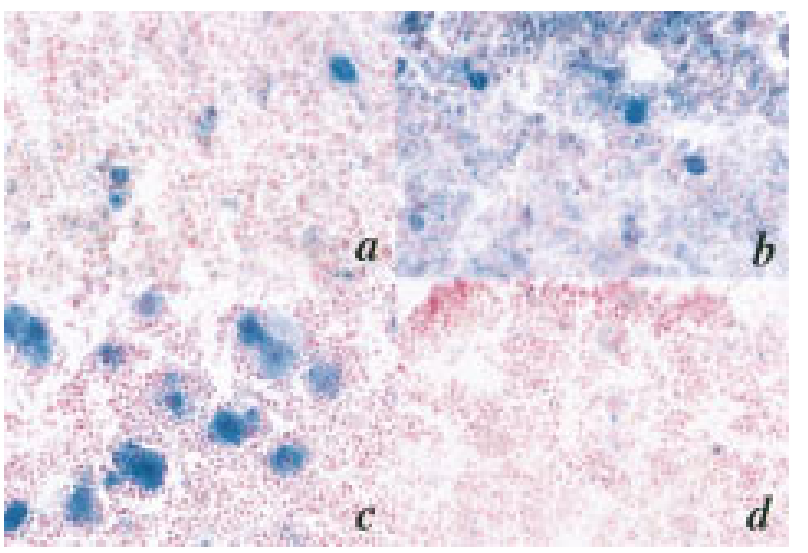

Figure 5. Small maf expression in megakaryocytes. E12.5 fetal liver $(a, b)$ and adult bone marrow $(c, d)$ were isolated, fixed, and stained for lacZ expression as described (Materials and methods). (a) mafG $^{-1-}$ and mafK ${ }^{-1-}$ (b) E12.5 embryos display similar intensities of $\beta$-gal activity in fetal liver megakaryocytes. (c) mafG exhibits intense expression in adult mutant megakaryocytes, whereas mafK expression is much weaker (d).

karyocytes (Fig. 5c), mafK was only weakly expressed there (Fig. 5d). These data indicate that mafG is the predominant small $\mathrm{M}$ af protein functioning in thrombopoiesis during the adult stage.

We sought to understand the underlying mechanism responsible for the behavioral phenotype. Motor behavior is a product of first sensing body position, followed by the ability to respond and modulate this position. The former function is performed by the vestibular system (saccule and utricle) and the semi-circular canals of the inner ear, whereas the latter is carried out by the cerebellum. We postulated that either (or possibly both) of these tissues might represent sites of prominent mafG expression. If so, and if mafK were not expressed there, then a tissue defect at either site would become an excellent candi date as the basis of the observed neurological mafG ${ }^{-1-}$ mutant phenotypes.

Because the area of the inner ear is firmly embedded in bone in adults and decalcification would destroy any $\beta$ gal activity there, we examined the developing vestibular system in newborn animals. These experiments showed that vestibular ganglia and sensory cells of the saccule specifically expressed mafG, but not mafK (Fig. 6a; data not shown). In addition, mafG was expressed strongly in the cerebellum (Fig. 6b), whereas mafK was not (Fig. 6c). Therefore, it is possible that deficiencies in either or both of these neurological systems may underlie the observed behavioral deficits.

\section{Discussion}

We have carried out a genetic loss-of-function analysis for two of the three small Maf proteins, and also have analyzed the expression profiles of these two small maf genes using a $\beta$-gal reporter inserted into each locus. Whereas $M$ afG and $M$ afK display overlap in expression at several sites and during several periods where the two might provide compensatory activity, there are also many sites and times during devel opment where expression of the two factors is not overlapping, and therefore they certainly cannot compensate for one anothers' activities there. We show here that, individually, MafG and $M$ afK are both dispensable for mouse viability and fertility. In each homozygous null mutant animal, the remaining two small $\mathrm{M}$ af proteins can presumably compensate for the loss of any one. These data also show, however, that there are at least two functions for $M$ afG, in megakaryocyte differentiation and neural development, which are not fully compensated by residual M afK and/or M afF expression. These results therefore provide the first direct proof that the small $M$ af proteins are required for specific physiological functions during development.

One of the three major mafG ${ }^{-1}$-specific phenotypes is thrombocytopenia. This phenotype is especially intriguing in that, in mice bearing a p45 gene disruption, 90\% of the homozygous mutants die of severe hemorrhage, secondary to nearly compl ete thrombocytopenia caused by a late block in megakaryocyte maturation (Shivdasani et al. 1995). Similarly, M afG-deficient mice are impai red in producing platelets, but do not show a propensity to hemorrhage. The most likely interpretation of these data

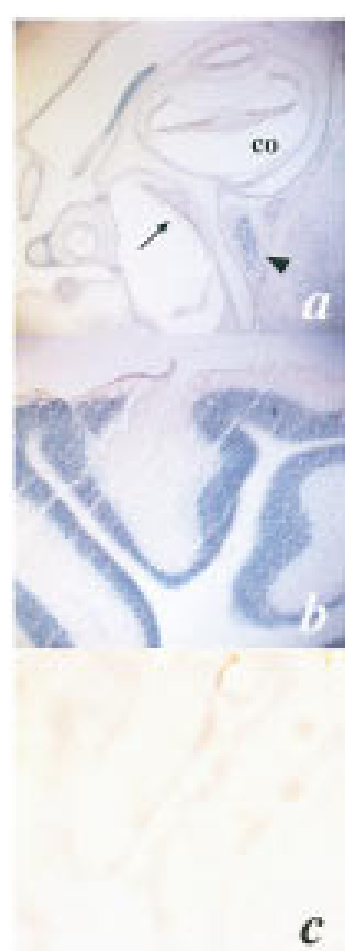

Figure 6. N euronal mafG and mafK expression. N ewborn and adult mice were sacrificed, their organs dissected, fixed, and stained for $\beta$-gal activity as described ( $M$ aterials and methods). (a) The inner ear of newborn pups shows mafG expression in the vestibulocochlear ganglion (arrowhead) and saccule sensory epithel ium (arrow). (b) Adult cerebellar Purkinje and granular cells exhibit high levels of mafG, but no detectable mafK (c). (co) Cochlea. 
is that M afG is the predominant partner molecule of p45 during megakaryopoiesis. Presumably a low level of residual $\mathrm{M}$ afK and/or M afF expression in megakaryocytes partially sustains thrombopoiesis, and therefore the phenotype of $M$ afG deficiency is less severe than the loss of p45 (i.e., the mafG loss-of-function mutation is a hypomorphic phenocopy of the homozygous p45 mutation). In addition to the platelet deficiency, the number of megakaryocytes increases in the bone marrow and spleens of mafG mutant animals. This may be attributable to a combination of maturation arrest at the final stage of megakaryocytic differentiation caused by a lack of active N F-E2 (p45:M afG heterodimer) activity, as well as to a compensatory homeostatic increase in megakaryocyte proliferation induced in response to the decreased platel et number.

The second phenotype displayed by mafG ${ }^{-1-}$ mice is age-dependent behavioral abnormalities. In two simple behavioral tasks, mafG homozygous mutant adults were quantifiably different than their wild-type and heterozygous littermates, confirming suspicions of a vestibular, neurol ogical, or muscl e defect, whereas the results of the balancing task imply that the defect is probably not muscular in origin. Furthermore, there are quite distinct differences in expression of the two proteins in the CNS, where M afG / lacZ is far more strongly expressed, implying that $M$ afG is also much more abundant (in the forebrain, midbrain, cerebellum, retinal ganglion cell layer, and the sensory epithelium of the internal ear) than is $M$ afK. We conclude that loss of MafG results in a neurological defect, probably within the cerebellum or the inner ear, al though the detailed physiological abnormalities specifically responsible for the observed behavioral phenotypes are yet to be determined.

Tracing the "knock-in" reporter gene activity during embryogenesis defined a strikingly distinct pattern of expression of the mafG and mafK genes as early as E6.5. At this point in development, the expression of these two small $M$ afs essentially defines the junction between extraembryonic and embryonic tissues. On the other hand, especially after birth, the expression patterns of MafG and $M$ afK expand and become complex, encompassing many different tissues and organs. In particular, we note that many sites of expression are proliferating tissues, such as epidermis, hair follicles, digestive and respiratory tract epithelia, and bone marrow, implying that the small Mafs may also have a role in cell growth or division.

The embryonic expression patterns and apparent lack of embryonic developmental phenotypes for mafG- and mafK-mutant mice beg the question: Do these small $M$ afs compensate for one another during development? There are two possible ways in which such compensation could occur. When one of the small $M$ af genes is mutated, the overlapping expression of another might contribute to the required activity. Alternatively, ablation of one gene could induce the expression of either one or both of the two remaining small maf genes in that tissue. These possibilities should be considered for several key times and sites of small maf expression, such as the yolk sac from E9.5-10.5, or in the fetal liver at E12.5, where both of these small $M$ af proteins are expressed at high levels. To determine if these represent important sites and/or times during development when the small maf genes must compensate for one another, it will be necessary to generate and examine compound mafG $^{-1-}:$ : mafK ${ }^{-1-}$ mutant animals. If these genes are compensatory in the yolk sac or fetal liver, one should observe lethality in the compound mutants before, or during, this crucial period (E9.5-E12.5) when the embryo switches from primitive to definitive hematopoiesis (Copp 1995). Strong expression of mafG and mafK is also detected in the ectoplacental cone beginning at E8.5 and continues in the placenta through E14.5, so the possibility also exists that uncompensated compound mutants might die during this time frame. In the latter scenario, the small Mafs could be critical for forming a normal placenta to ensure the transition from diffusion-based to placental nutrition (Copp 1995). These intercross mating experiments, as well as detailed expression analysis of the small M afs in the mutant mice, are ongoing.

\section{Materials and methook}

Construction and preparation of targeting vectors

The vector ploxPneol (the gift of A. Nagy, M ount Sinai Hospital, Toronto, Ontario, Canada) was used to construct the mafK targeting vector. It contains a mutant neomycin resistance gene derived from pPNT (Tybulewicz et al. 1991) flanked by loxP sites and driven by the mouse PGK promoter. To construct ploxPneo-HA-SS- $\beta$-gal, the Smal-Notl and Notl-Sall fragments (coding region and poly(A) signal of Escherichia coli $\beta$ gal, respectively) were excised from pSV $\beta$ (Clontech) and cloned into the EcoRV and HindlII-Sall sites of pBluescript SK + (pBS), respectively ( $\mathrm{p} \beta$-gal). N ext, a 1.8-kb Smal-Smal fragment containing $5^{\prime}$ genomic sequence and exon IN was inserted into the pBS EcoRI site of $\mathrm{p} \beta$-gal. Finally, an Xhol-HindlII fragment that contains the herpes simplex thymidine kinase gene flanked by polyoma virus enhancers (PyTK; Mansour et al. 1988) was inserted into the Smal site in the pBS polylinker. Ligation of blunted Xhol and Smal sites regenerated the Xhol site, and a clone with this Xhol site opposite $\beta$-gal was selected, and designated pTK-SS- $\beta$-gal.

A $6.6-\mathrm{kb}$ HindllI-Ascl genomic fragment of mafK containing the $3^{\prime}$ end of the third exon and $3^{\prime}$ flanking sequences was cloned into the Smal site of ploxPneol (ploxPneo-HA). N ext, the Xhol fragment from pTK-SS- $\beta$-gal, consisting of PyTK, mafK sequences, and $\beta$-gal, was inserted into the Xhol site of ploxPneo-HA, thus completing ploxPneo-HA-SS- $\beta$-gal (ploxPneo- $\beta$-gal ). This vector del eted the second and third (both coding) exons, and left $\beta$-gal under control of the mafk locus.

The mafG targeting vector was constructed using the plasmid pN ATA (the generous gift of $\mathrm{Y}$. N abeshima, $\mathrm{N}$ ational Institute of N euroscience, Tokyo, Japan). This plasmid contains the neomycin resistance and thymidine kinase (neo/TK) genes, each driven by individual MC1 promoters ( $M$ ansour et al. 1988) and flanked by loxP sites. The gene for diphtheria toxin subunit $A$ (DT), al so transcriptionally directed by the $\mathrm{MC} 1$ promoter, was added for negative selection. A 1.4-kb Sacl-Smal genomic fragment containing the $5^{\prime}$ end of the second exon was inserted into the EcoRI site of $p \beta$-gal, creating pScSm- $\beta$-gal. An 8.0-kb EcoR$V$-Sall genomic fragment downstream from the presumed third exon was inserted into the Hpal site of pNATA (pNATA-EVSI). 


\section{Shavit et al.}

Finally, the Notl-Sall fragment from pScSm- $\beta$-gal was cloned into the Sall site of pN ATA-EVSI, creating the targeting Vector pN ATA-DT-EVSI. This construct deleted the second and third exons, leaving lacZ under control of the mafG locus.

\section{Gene targeting in ES cells}

R1 ES cells ( $\mathrm{N}$ agy et al. 1993) were cultured on mitomycin Ctreated primary mouse embryonic fibroblast feeders (prepared according to Hogan et al. 1994) on gelatinized tissue culture plates essentially as described (Wurst and Joyner 1993). The medium consisted of high glucose Dulbecco's Modified Eagle M edium (DMEM) and 15\% fetal bovine serum (FBS, HyClone), supplemented with non-essential amino acids, glutamine, sodium pyruvate, $\beta$-mercaptoethanol, penicillin/streptomycin, and 1000 units $/ \mathrm{ml}$ of leukemia inhibitory factor (ESGRO, GIBCO-BRL).

ploxPneo- $\beta$-gal and pNATA-DT-EVSI were linearized with $\mathrm{N}$ otl, extracted with phenol:chloroform, precipitated, and resuspended in TE buffer. The R1 cells were trypsinized and resuspended in either PBS or ES medium, and from 5.6 to $10 \times 10^{6}$ cells were el ectroporated with $25 \mu \mathrm{g}$ of linearized targeting vector at $240 \mathrm{~V}, 500 \mu \mathrm{F}$, and placed on ice for $20 \mathrm{~min}$. Each cuvette was subsequently plated on a $100-\mathrm{mm}$ plate of feeder cells derived from a mouse containing the gene for neomycin resistance (Genome Systems or The Jackson Laboratory). The cells were cultured for 24-48 hr before G418 (GIBCO-BRL) and Gancyclovir (Syntex) were added at concentrations of $210 \mu \mathrm{g} / \mathrm{ml}$ (active component) and $2 \mu \mathrm{m}$, respectively. M edium was changed daily, and sel ection was maintained for 8 days, by which time colonies were visible to the naked eye.

Individual colonies were picked under 10-40 ×magnification, grown on feeders in 96-well plates, and replica-plated, using one plate for DNA and the other as a frozen stock, as described (Ramirez-Solis et al. 1992). In the case of mafK targeting, 68 colonies were screened by Southern blotting using a $5^{\prime}$ external probe (a 0.6-kb Xbal fragment 2.0-kb $3^{\prime}$ to exon IM), which identified 5 colonies with a $10.0-\mathrm{kb}$ mutant Bglll fragment in addition to the $6.9-\mathrm{kb}$ endogenous fragment. For mafG, PCR screening was performed using a $5^{\prime}$ primer just upstream of the short arm Sacl site, and a $3^{\prime}$ primer in the $5^{\prime}$ region of the lac $Z$ gene. Twenty-one clones were identified, yielding a targeting frequency of 1 in 22. Eight were confirmed by Southerns to be properly targeted cl ones by the presence of a polymorphic 6.4-kb BamHI fragment, in addition to the wild-type 5.3-kb fragment.

Generation of mutant mice

Chimeric mice were derived as described ( $\mathrm{N}$ agy and Rossant 1993) except that single eight-cell diploid embryos from CD1 egg donors (Charles River) were used for each aggregation. The aggregates were cultured overnight, and 8-12 blastocysts were transferred to each uterine horn of pseudopregnant CD1 females. Chimeras of greater than $50 \%$ ES cell contribution (estimated by coat color) were mated to CDI femal es. Three mafK and two mafG targeted ES clones passed the mutation to $F_{1}$ offspring. Subsequently, the transmitting chimeras were mated to $\mathrm{C} 57 \mathrm{BL} / 6 \mathrm{~J}$ mice to transfer the mutant allele to this background.

Genotyping of progeny was done by Southern blot and PCR analysis of tail DNA (Hogan et al. 1994). Briefly, the tips of mouse pup tails were digested overnight in lysis buffer [100 mM $\mathrm{NaCl}, 1.0 \%$ SDS, $50 \mathrm{~mm}$ Tris (pH 8.0), 100 mM EDTA (pH 8.0), $0.35 \mathrm{mg} / \mathrm{ml}$ fresh proteinase $\mathrm{K}$ ] at $55^{\circ} \mathrm{C}$, phenol/chloroform extracted, and precipitated. For PCR analysis, a common primer $5^{\prime}$ to exon 2 and two al ternative $3^{\prime}$ primers were designed to detect the three classes of progeny in a single PCR reaction. The $3^{\prime}$ primer that detected the wild-type allele was in the second intron, whereas the $3^{\prime}$ mutant all el e primer corresponded to the 5 region of the lacZ gene.

\section{Staining for lacZ gene ( $\beta$-gal) activity}

The inserted lac $Z$ gene was used to follow the small maf expression pattern by staining with X-gal (5-bromo-4-chloro-3indolyl- $\beta$-D-galactoside). 129/CD1 hybrid mice were used for these experiments. $\mathrm{N}$ oon on the day that a copulation plug was detected was considered day 0.5 of pregnancy. Pregnant females were sacrificed on the desired dates, and embryos were dissected and then immersed in fixative ( $1 \%$ formal dehyde, $0.2 \%$ glutaraldehyde, $0.02 \% \mathrm{NP}-40$ in PBS) at $4^{\circ} \mathrm{C}$ for $2 \mathrm{hr}$. After washing with PBS, the embryos were soaked in $20 \%$ sucrose overnight, and then embedded in OCT compound (Tissue-Tek, Sakura) and sectioned in a cryostat at $-20^{\circ} \mathrm{C}$. Subsequently, the embryos were stained with $\mathrm{X}$-gal solution [0.1 $\mathrm{m}$ sodium phosphate at $\mathrm{pH}$ 7.3, $2 \mathrm{~mm} \mathrm{M} \mathrm{gCl}_{2}, 5 \mathrm{mM} \mathrm{K}_{3} \mathrm{Fe}(\mathrm{CN})_{6}, 5 \mathrm{~mm} \mathrm{~K}{ }_{4} \mathrm{Fe}(\mathrm{CN})_{6}, 0.01 \%$ sodium deoxycholate, $0.02 \% \mathrm{~N} \mathrm{P}-40,20 \mathrm{~mm}$ Tris- $\mathrm{HCl}, 1 \mathrm{mg} / \mathrm{ml}$ of $\mathrm{X}$-gal ] at $37^{\circ} \mathrm{C}$ overnight, and counterstained with nuclear fast red. Alternatively, embryos younger than E9.5 were usually stained at $30^{\circ} \mathrm{C}$ after fixation, and then processed as described above.

Assaying for glycoprotein IIb immunoreactivity and acetylcholinesterase activity

Femurs from 2- to 4-month-old mafG $^{-1-}$ animals were dissected and opened before fixation in $4 \%$ paraformal dehyde for $2 \mathrm{hr}$ at $4^{\circ} \mathrm{C}$, followed by overnight immersion in $20 \%$ sucrose. Bone marrow was then removed and embedded in OCT compound (Tissue-Tek, Sakura) and sectioned in a cryostat at $-20^{\circ} \mathrm{C}$. We incubated a new rat anti-mouse glycoprotein IIb monoclonal antibody ( $M$. Y amamoto, unpubl.) with the sectioned bone marrow, followed by incubation with horseradish peroxidase-conjugated anti-rat IgG. Diaminobenzidine was used as chromogen, labeling positive cells with a brown color, followed by counterstaining with methyl green.

Acetylcholinesterase activity was determined essentially as described (Jackson 1973). Briefly, the sectioned bone marrow was incubated for $1 \mathrm{hr}$ at $37^{\circ} \mathrm{C}$ in a freshly prepared buffer containing $10 \mathrm{mg}$ of acetylthiocholine iodide (Sigma) dissolved in $15 \mathrm{ml}$ of $0.1 \mathrm{M}$ sodium phosphate $(\mathrm{pH} 6.0)$, with $1 \mathrm{ml}$ of $0.1 \mathrm{M}$ sodium citrate, $2 \mathrm{ml}$ of $30 \mathrm{~mm}$ cupric sulfate, and $2 \mathrm{ml}$ of $5 \mathrm{~mm}$ potassium ferricyanide. Positive cells became orange, and he matoxylin was used for counterstaining.

\section{Hematological analysis}

Four-month-old mice were euthanized with carbon dioxide and $0.5 \mathrm{ml}$ of blood was drawn from the inferior vena cava into a syringe containing 5-10 $\mu \mathrm{l}$ of $0.5 \mathrm{M}$ EDTA. The blood samples were analyzed by Anilytics, Inc. (Gaithersburg, MD).

The megakaryocyte percentage was determined by counting cells in the bone marrow. Femurs or tibias from mafG $^{+1-}$ and mafG $^{-1-}$ animals were dissected and flushed with PBS. Bone marrow cells were disaggregated by repeated flushing through a 21 gauge needle. $\mathrm{N}$ on-nucl eated cells were removed by osmotic lysis with a hypotonic $\mathrm{N} \mathrm{H}_{4} \mathrm{Cl}$ solution. The remaining cell suspension was counted in a $200 \mu \mathrm{m}$ depth hemocytometer to allow free flow of megakaryocytes. The megakaryocyte percentage was calculated as follows:

$$
\text { megakaryocyte } \%=\frac{\text { megakaryocyte count }}{\text { nucleated cell count }} \times 100
$$


Behavioral analysis

$F_{2}(129 / B 6)$ mafG $^{+1-}$ and mafG ${ }^{-1-}$ mice were intercrossed to generate $\mathrm{F}_{3}$ pups for behavioral testing. Animals were tested at 3-6 months of age. For the wire hang test, a wire $\sim 2 \mathrm{~mm}$ in diameter was employed. Mice were allowed to grab the wire with their forepaws, and then released so their hindlimbs dangled below. Timing was initiated after the mice were released, for a maximum of $1 \mathrm{~min}$. For the balancing task, the mice were placed on a $10-\mathrm{ml}$ pi pette with their $\mathrm{A} / \mathrm{P}$ axis parallel to the pi pette. A gain, timing began after the mice were rel eased, with a 1 min limit.

\section{Weights}

Mice were weighed on a balance that measured to the nearest 0.1 gram. Mice younger than 5 days old (P5) were wei ghed to the nearest 0.1 gram. Mice older than 5 days were weighed to the nearest 0.5 gram because of their increased activity. The entire litter was examined at every time point for reference. To control for variation between different litters, a normalized percentage (norm\%) was cal culated as follows, where "normal litter mean" is the average weight of ++ and $+/$-animals from a particular litter at a particular time point.

$$
\text { norm } \%=\frac{\text { individual weight }}{\text { normal litter mean }} \times 100
$$

\section{Acknowledgments}

We thank $Y$. Tanimoto and J. Fan for outstanding technical assistance; D. Williams, J. Rossant, A. N agy, M. Gertsenstein, and $A$. Cheng for advice on ES cell culture and morula aggregation; $\mathrm{Y}$. N abeshima for the pN ATA plasmid; A. Nagy for ploxPneol; M. Capecchi for PyT K; L. Sol berg and F. Turek for advice on open field testing; and R. Paylor and M. M cDonal d for advice on behavioral analysis. We al so thank J. Bungert, K. Igarashi, T. Komeno, Q. Liu, K. Tanimoto, K.-C. Lim, and R. Yu for advice and encouragement. This work was supported by a M edical Science Training Program training grant to N orthwestern University (GM 08152; J.A.S.) and research grants from the M inistry of Education, Science, Sports and Culture (H.M. and M.Y.), the Japanese Society for Promotion of Sciences (M.Y.), and the N ational Institutes of Health (HL24415 and GM 28896; J.D.E.).

The publication costs of this article were defrayed in part by payment of page charges. This article must therefore be hereby marked "advertisement" in accordance with 18 USC section 1734 solely to indicate this fact.

\section{References}

Andrews, N.C., H. Erjument-Bromage, M.B. Davidson, P. Tempst, and S.H. Orkin. 1993a. Erythroid transcription factor N F-E2 is a haematopoietic-specific basic-leucine zipper protein. Nature 362: 722-728.

Andrews, N.C., K.J. Kotkow, P.A. N ey, H. Erdjument-Bromage, P. Tempst, and S.H. Orkin. 1993b. The ubiquitous subunit of erythroid transcription factor N F-E2 is a small basic-leucine zipper protein related to the v-maf oncogene. Proc. Natl. Acad. Sci. 90: 11488-11492.

Beckstead, J.H., P.E. Stenberg, R.P. M cEver, M.A. Shuman, and D.F. Bainton. 1986. Immunohistochemical localization of membrane and al pha-granule proteins in human megakaryocytes: Application to plastic-embedded bone marrow biopsy specimens. Blood 67: 285-293.
Blank, V. and N.C. Andrews. 1997. The Maf transcription factors: Regulators of differentiation. Trends Biol. Sci. 22: 437441.

Caterina, J.J., D. Donze, C.-W. Sun, D.J. Ciavatta, and T.M. Townes. 1994. Cloning and functional characterization of LCR-F1: A bZIP transcription factor that activates erythroidspecific, human globin gene expression. Nucleic Acids Res. 22: 2383-2391.

Chan, J.Y., X.-L. Han, and Y.-W. Kan. 1993. Cloning of N rfl, an NF-E2-related transcription factor, by genetic selection in yeast. Proc. Natl. Acad. Sci. 90: 11371-11375.

Chan, K., R. Lu, J.C. Chan, and Y.W. Kan. 1996. N RF2, a member of the N FE2 family of transcription factors, is not essential for murine erythropoiesis, growth, and development. Proc. Natl. Acad. Sci. 93: 13943-13948.

Copp, A.J. 1995. Death before birth: Clues from gene knockouts and mutations. Trends Genet. 11: 87-93.

Crawley, J.N . and R. Paylor. 1997. A proposed test battery and constellations of specific behavioral paradigms to investigate the behavioral phenotypes of transgenic and knockout mice. Hor. \& Behav. 31: 197-211.

Engel, J.D. 1994. Meticulous AP-1 factors [Maf]. Nature 367: 516-517.

Farmer, S.C., C.W. Sun, G.E. Winnier, B.L. Hogan, and T.M. Townes. 1997. The bZIP transcription factor LCR-F1 is essential for mesoderm formation in mouse development. Genes \& Dev. 11: 786-798.

Fujiwara, K., T.K. Kataoka, and M. Nishizawa. 1993. Two new members of the maf oncogene family, mafK and mafF, encode nuclear b-Zip proteins lacking putative trans-activator domain. Oncogene 8: 2371-2380.

Hogan, B., R. Beddington, F. Costantini, and E. Lacy. 1994. Manipulating the mouse embryo. Cold Spring Harbor Laboratory Press, Cold Spring Harbor, NY.

Igarashi, K., K. Kataoka, K. Itoh, N. Hayashi, M. Nishizawa, and M. Yamamoto. 1994. Regulation of transcription by dimerization of erythroid factor NF-E2 p45 with small Maf proteins. Nature 367: 568-572.

Itoh, K., K. Igarashi, N. Hayashi, M. Nishizawa, and M. Yamamoto. 1995. Cloning and characterization of a novel erythroid cell-derived CNC family transcription factor heterodimerizing with the small M af family proteins. Mol. Cell. Biol. 15: 4184-4193.

Itoh, K., T. Chiba, S. Takahashi, T. Ishii, K. Igarashi, Y. Katoh, T. Oyake, N. Hayashi, K. Satoh, I. Hatayama, M. Yamamoto, and $\mathrm{Y}$. N abeshima. 1997. An N rf2/small Maf heterodimer mediates the induction of phase II detoxifying enzyme genes through antioxidant response elements. Biochem. Biophys. Res. Comm. 236: 313-322.

Jackson, C.W. 1973. Cholinesterase as a possible marker for early cells of the megakaryocytic series. Blood 42: 413-421.

Johnsen, O., N . Skammel srud, L. Luna, M. N ishizawa, H. Prydz, and A.B. Kolsto. 1996. Small M af proteins interact with the human transcription factor TCF11/N rf1/LCR-F1. Nucleic Acids Res. 24: 4289-4297.

Kataoka, K., K.T. Fujiwara, M. N oda, and M. N ishizawa. 1994a. $M$ afB, a new $M$ af family transcription activator that can associate with $\mathrm{M}$ af and Fos, but not with Jun. Mol. Cell. Biol. 14: 7581-7591.

Kataoka, K., M. N oda, and M. Nishizawa. 1994b. Maf nuclear oncoprotein recognizes sequences rel ated to an AP-1 site and forms heterodimers with both Fos and Jun. Mol. Cell. Biol. 14: 700-712.

Kataoka, K., K. Igarashi, K. Itoh, K.T. Fujiwara, M. N oda, M. Yamamoto, and M. Nishizawa. 1995. Small Maf proteins heterodimerize with Fos and may act as competitive repres- 
sors of the NF-E2 transcription factor. Mol. Cell. Biol. 15: $2180-2190$.

Kotkow, K.J. and S.H. Orkin. 1996. Complexity of the erythroid transcription factor in N F-E2 as reveal ed by gene targeting of the mouse p18 N F-E2 locus. Proc. Natl. Acad. Sci. 93: 35143518.

Luna, L., O. Johnsen, A.H. Skartlien, F. Pedeutour, C. TurcCarel, H. Prydz, and A.B. Kolsto. 1994. Molecular cloning of a putative novel human bZIP transcription factor on chromosome 17q22. Genomics 22: 553-562.

Mansour, S.J., K.R. Thomas, and M.R. Capecchi. 1988. Disruption of the protooncogene int-2 in mouse embryo-derived stem cells: A general strategy for targeting mutations to nonselectable genes. Nature 336: 348-352.

Mohler, J., K. Vani, S. Leung, and A. Epstein. 1991. Segmentally restricted, cephalic expression of a leucine zipper gene during Drosophila embryogenesis. Mech. Dev. 34: 3-9.

Moi, P., K. Chan, I. Asunis, A. Cao, and Y.W. Kan. 1994. Isolation of N F-E2-related factor 2 (N rf2), a N F-E2-like basic leucine zipper transcriptional activator that binds to the tandem NF-E2/AP1 repeat of the beta-globin locus control re gion. Proc. Natl. Acad. Sci. 91: 9926-9930.

Motohashi, H., K. Igarashi, K. Onodera, H. Ohtani, M. Nishizawa, J.D. Engel, and M. Yamamoto. 1996. Mesodermalversus neuronal-specific expression of $M$ afK is regulated by alternative promoters. Genes Cells 1: 223-238.

M otohashi, H., J.A. Shavit, K. Igarashi, M. Yamamoto, and J.D. Engel. 1997. The world according to M af. Nucleic Acids Res. 25: 2953-2960.

Nagai, T., K. Igarashi, J. Akasaka, K. Furuyama, H. Fujita, N. Hayashi, M. Yamamoto, and S. Sassa. 1998. Regulation of NF-E2 activity in erythroleukemia cell differentiation. J. Biol. Chem. 273: 5358-5365.

Nagy, A. and J. Rossant. 1993. Production of completely ES cell-derived fetuses. In Gene targeting: A practical approach (ed. A.L. Joyner), pp. 147-179. IRL Press, Oxford, UK.

Nagy, A., J. Rossant, R. N agy, N.W. Abramow, and J.C. Roder. 1993. Derivation of completely cell culture-derived mice from early-passage embryonic stem cells. Proc. Natl. Acad. Sci. 90: 8424-8428.

Nishizawa, M., K. Kataoka, N. Goto, K. Fujiwara, and S. Kawai. 1989. v-maf, a viral oncogene that encodes a "leucine zipper" motif. Proc. Natl. Acad. Sci. 86: 7711-7715.

Oyake, T., K. Itoh, H. M otohashi, N. Hayashi, H. Hoshino, M. Nishizawa, M. Yamamoto, and K. Igarashi. 1996. Bach proteins belong to a novel family of BTB-basic leucine zipper transcription factors that interact with $\mathrm{M}$ afK and regulate transcription through the NF-E2 site. Mol. Cell. Biol. 16: 6083-6095.

Ramirez-Solis, R., J. Rivera-Perez, J.D. Wallace, M. Wims, H. Zheng, and A. Bradley. 1992. Genomic DNA microextraction: A method to screen numerous samples. Anal. Biochem. 201: 331-335.

Shivdasani, R.A., M.F. Rosenblatt, D.C. Zucker-Franklin, W. Jackson, P. Hunt, C.J. Saris, and S.H. Orkin. 1995. Transcription factor NF-E2 is required for platel et formation independent of the actions of thrombopoietin/ M GDF in megakaryocyte development. Cell 81: 695-701.

Swaroop, A., J. Xu, H. Pawar, A. Jackson, C. Skolnick, and N. Agarwal. 1992. A conserved retina-specific gene encodes a basic motif/leucine zipper protein. Proc. Natl. Acad. Sci. 89: $266-270$.

Tybulewicz, V.L., C.E. Crawford, P.K. Jackson, R.T. Bronson, and R.C. Mulligan. 1991. N eonatal lethality and lymphopenia in mice with a homozygous disruption of the c-abl protooncogene. Cell 65: 1153-1163.
Wurst, W. and A.L. Joyner. 1993. Production of targeted embryonic stem cell clones. In Gene targeting: A practical approach (ed. A.L. Joyner), pp. 33-61. IRL Press, Oxford, UK. 


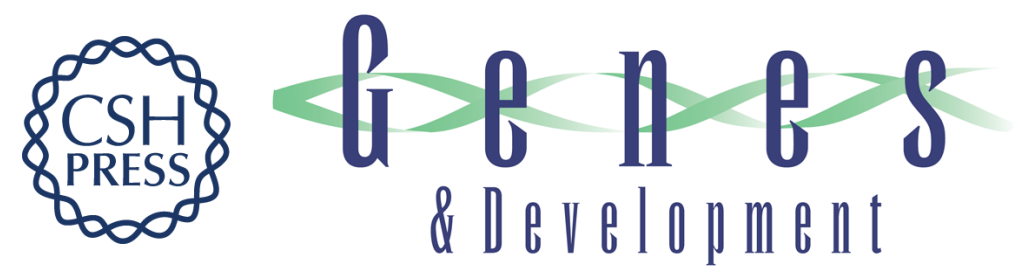

\section{Impaired megakaryopoiesis and behavioral defects inmafG-null mutant mice}

Jordan A. Shavit, Hozumi Motohashi, Ko Onodera, et al.

Genes Dev. 1998, 12:

Access the most recent version at doi:10.1101/gad.12.14.2164

References This article cites 34 articles, 17 of which can be accessed free at: http://genesdev.cshlp.org/content/12/14/2164.full.html\#ref-list-1

License

Email Alerting Receive free email alerts when new articles cite this article - sign up in the box at the top Service right corner of the article or click here.

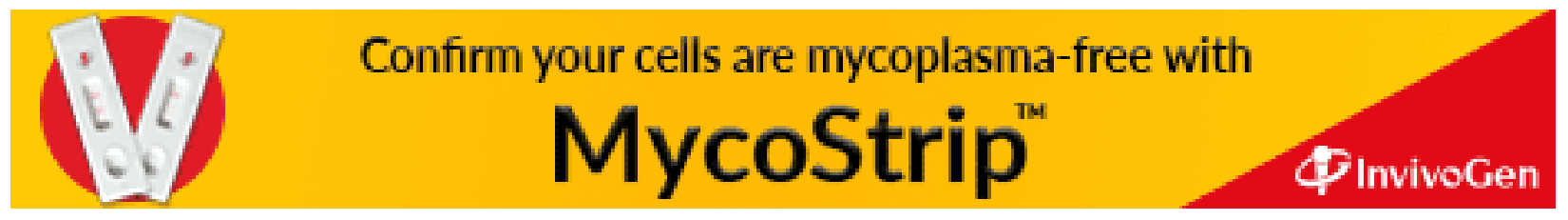

